\title{
Tidal volume monitoring by a set of tetrapolar impedance measurements selected from the 16-electrodes arrangement used in Electrical Impedance Tomography (EIT) technique. Calibration equations in a group of healthy males.
}

\author{
M. Balleza-Ordaz ${ }^{1}$, E. Alday-Perez ${ }^{1}$, M. Vargas-Luna ${ }^{1}$, S. Kashina ${ }^{2}$, M.R. Huerta-Franco ${ }^{3}$, L.A. \\ Torres-González ${ }^{4}$, P.J. Riu-Costa ${ }^{5}$ \\ ${ }^{1}$ Universidad de Guanajuato. Science and Engineering Department, León, Guanajuato, Mexico. \\ ${ }^{2}$ Universidad de Guanajuato. Biology Department, Guanajuato, Guanajuato, Mexico. \\ ${ }^{3}$ Universidad de Guanajuato. Health Sciences Division, Department of Applied Sciences to Work, León, \\ Guanajuato, Mexico. \\ ${ }^{4}$ Universidad Iberoamericana. Research and Postgraduate Department, León Guanajuato, México. \\ ${ }^{5}$ Universitat Politècnica de Catalunya. Electronics and Biomedical Instrumentation Department, Barcelona, \\ Spain.
}

Email: marco.balleza@fisica.ugto.mx

Telephone: 00 (52) 477 788-51-00 Ext: 8472 and 8475

Total number of word of the manuscript: 5737 words.

The number of words of the abstract: 298 words.

The number of figures: 3 figures.

The number of tables: 6 tables.

\begin{abstract}
Previously, our research group obtained a set of calibration equations for being used by a device of electrical impedance tomography (EIT) and transform the impedance changes into a measurable volume signal in a group of healthy males. The mathematical adjustment of calibration equations were acceptable for respiration monitoring in clinical environment. For this case, the impedance variations were obtained from a set of EIT images that were reconstructed by an algorithm using a set of impedance matrixes (IEITM). Each element of IEITM depicts a set of impedance changes taken from the main arrangement of 16 electrodes. Now, our main challenge is to replace the EIT image by a 4-electrodes configuration to monitor breathing. For this purpose, we statistically compared the tetrapolar impedance changes obtained from IEITM and the volume determinations obtained by pneumotachometer (gold standard) in order to determine the optimal 4-electrodes configuration. Subsequently, for each configuration a set of 20 calibration equations were obtained. It was also compared those results determined by using EIT image. From the obtained results, it was evidenced that the best configurations were with electrodes 3-4 and 11-12 and the electrodes 4-5 and 12-13. The mean of $\mathrm{R}^{2}$ of the 20 calibration equations determined by EIT image, the configuration of electrodes 3-4/11-12 and the electrodes 4-5/12-13 were $0.943 \pm 0.010,0.848 \pm 0.062$ and $0.690 \pm 0.122$, respectively. The error (\%) of volume determinations obtained by EIT, using EIT image, 3-4/11-12 and 4-5/12-13, respect those obtained by pneumotachometer were of $15 \pm 6 \%$, $16 \pm 4 \%$ and $43 \pm 41 \%$, respectively. From the statistical comparison of the errors, it is evidenced that volume differences obtained by EIT, using image and configuration of electrodes 3-4/11-12, not showed statistically significant differences. So, we concluded that the EIT image and the configuration 3-4/11-12 are exchangeable. So, it is possible to use this 4 electrodes arrangement for respiration monitoring.
\end{abstract}

Keywords. Electrical impedance tomography, tetrapolar impedance measurements, tidal volume, respiration. 


\section{Introduction}

Nowadays, in medical areas, there is nothing good enough to follow in a non-invasive way the respiratory pattern (RP). The importance of the RP monitoring is that it provides information about the organs that control respiration and the neuromuscular disorders suffering by patients [1-2]. There are different devices used to monitor RP. The majority of them are expensive and can be used only at sanitary centers. The pneumotachometer is the method of reference to follow RP. However, it overestimates the volume determinations between the $15 \%$ and 35\% by the essential use of a mouth piece and clip nose [3-6]. This device is mainly used in effort respiratory trials [7]. Other device used to monitor breathing is the respiratory inductance plethysmography (RIP). This equipment obtains a volume signal through the thoracic and abdominal movements recorded by two inductive bands. The main drawback of RIP is the recalibration due to the movements of the bands, causing an overestimation of volume measurements [8-10]. Exist other respiratory monitoring systems based on transducers of turbine and heat flux sensors. The turbine devices obtains a volume signal from the rotational speed of a turbine. The heat sensors flux devices use a metallic filament whose resistance values depend on temperature. The temperature of filament varies by the exhaled air. Both kind of monitoring systems are not accurate and it is possible to obtain a qualitative volume signal. These devices are used to follow respiration in obstructive sleep apena/hypopnea patients [11].

A new technique developed by different research groups for being used in clinical environment is the electrical bioimpedance (E.BI). E.BI measurements are based on the injection of an electrical current and the detection of a voltage (or vice versa) in a biological tissue. This method is used for characterizing the biological tissues. Some applications of E.BI in different clinical areas are 1) analysis and characterization of cells from its static and dynamic behavior [12-14], 2) cell quantification by a Coulter counter, method widely used in hospital environment [15], 3) body mass composition measuring [16-19], 4) cardiac volume-minute monitoring [20-21], 5) assessment of the degree of cardiac graft rejection in post-transplanted patients [22] and 6) measurement of body fluid volume in patients with heart and kidney problems [23]. In all those studies, E.BI has proved its efficiency by obtaining promising results.

Some research groups have paid special attention in pneumology area. For example, Houtveen et al. assessed the RIP technique and the thoracic impedance changes derived from breathing to different rates and positions obtained by 4 spot electrodes against the spirometry parameters. From the obtained results, they concluded that both methods can be used to monitor different respiratory rates, even to detect changes in respiratory volume. Nonetheless, they detected large measurement errors using both methods. This limit their use in ambulatory area. So, taking into account the anthropometric features of each person and the respiration posture, the researchers proposed that a new method of calibration must be developed [24].

Other study was the performed by Roberts et al. They use the E.BI technique to detect and guide rescue ventilations (RV) in children between 6 months and 17 years. All volunteers were submitted to conventional mechanical ventilation. The RV are tidal volumes at a range between 7 and $10 \mathrm{ml} / \mathrm{kg}$. The impedance changes were obtained by using defibrillator electrode pads in the thoracic standard anterior-apical position (AA) and the thoracic anterior-posterior position (AP). The results evidenced that changes in thoracic impedance obtained by using defibrillator pads can accurately detect ventilation above $7 \mathrm{ml} / \mathrm{kg}$ in basal state, corresponding to rescue ventilations, in AA and AP positions. However, it was not possible to detect volumes less to $7 \mathrm{ml} / \mathrm{kg}$ [25].

Both researches revealed the challenge to detect ventilation by an electrical bioimpedance system. The impedance changes corresponding to lung ventilation were statistically significant compared to the volume changes obtained by a gold standard (spirometry parameters or pneumotachometer). However, in both studies a method of calibration for being used in E.BI system and monitor the breathing pattern was not suggested.

Another technique based on the acquisition of impedance measurements and used to analyze the respiratory pattern is the electrical impedance tomography (EIT). EIT is a technique of imaging which represent the impedance distribution in a cross-sectional area of human body [26-28]. The Images are created by the reconstruction of a set of tetrapolar impedance measurements taken from an arrangement of electrodes placed around the thorax. Its main application is in the pneumology area as, for example, the detection and quantification of liquid in lungs [29-30] or the pressure-volume obtaining curves [31-32]. 
In previous studies, our research group analyzed and adjusted the impedance changes corresponding to tidal volume obtained by EIT, using a set of calibration equations determined by whole EIT images [33] and different regions of interest (ROI) [34], in a group of healthy males. The obtained results revealed that the mathematical adjustment of calibration equations were acceptable for being used in clinical practice. In this case, the impedance information was taken from the thoracic perimeter. In this work, we decide to substitute the impedance information corresponding to whole EIT frame for 4-electrode configuration taken from main EIT electrodes arrangement. The tetrapolar impedance changes will be taken from the main impedance matrix used for reconstruct EIT images. Our main challenge is to find out the optimal 4-electrode configuration and obtain a set of calibration equations in order to adjust and transform the impedance changes into a measurable volume data.

\section{Material and methods}

\subsection{Pneumotachometer}

The pneumotachometer used to monitor the tidal volume was a Med Graphics preVentTM Pneumotach (Medical Graphics Corporation, St. Paul, MN, USA). It is controlled by software supplied by the manufacturer to record measurements of volume-time. These are displayed graphically on screen and numerically by downloading a text file. The pneumotachometer is calibrated by a 3-L syringe in accordance with standard laboratory protocols. In this research, the pneumotachometer was used as gold-standard.

\subsection{EIT device (TIE4sys)}

The TIE4sys is the fourth-generation of an EIT-prototype designed by the Electronic Engineering Department at the Universitat Politècnica de Catalunya, Barcelona, Spain. The TIE4sys uses 16 electrodes (Red Dot 2560 - 3M, London, Ontario, Canada). These are placed around the thoracic box at the level of the sixth intercostal space (see figure 1), following the protocol previously established by our research group [35]. To obtain a set of measurements, the EIT device injects an electrical current of $1 \mathrm{~mA}$ at $48 \mathrm{kHz}$ through a pair of adjacent electrodes. A differential voltage is sequentially recorded at the rest of adjacent electrode pairs. Once all potentials have been recorded for that injection electrode pair, the injection point and the voltage detection pairs are moved to the adjacent electrode pair, beginning a new cycle of measures. The procedure ends until all adjacent electrode pairs have been used as injectors and detectors. All determinations obtained by EIT are redundant, so it is possible to calculate the reciprocity error. This parameter describes the systematic errors and malfunctions present during the procedure (such as the poor contact of electrodes and skin) [36-37].

EIT is a referential technique that produces dynamic images. It uses a reference frame that is unique for each subject. This matrix is constructed by averaging 200 frames corresponding to 12 seconds of tidal respiration and depicts the initial state with respect to which conductivity changes will be acquired. Once breathing is recorded and EIT images are reconstructed, an impedance signal which is proportional to lung volume changes is obtained. This signal is determined by s set of EIT images and it is in terms of total impedance indexes (TII) estimated by the addition of the impedance changes corresponding to all voxels of each EIT image [38].

\subsection{Impedance EIT matrix}

The impedance EIT matrix (IEITM) is a frame composed by 16x16 elements in which the impedance determinations obtained by TIE4sys are recorded. Each voxel of IEITM depicts a configuration of 2-, 3- and 4electrodes depending on element position (see figure 2). The IEITM is processed by a Weighted Back-Projection (WBP) algorithm in order to obtain EIT dynamic images. The WBP algorithm uses a weight frame that takes into account the spatial sensitivity of IEITM's voxel [39]. The advantages of WBP are: 1) it is possible to obtain a lower computing time, and 2) it does not need expensive computational features (hardware and software) [4041]. In order to obtain the impedance changes corresponding to each IEITM's voxel, especially those obtained by 4-electrodes arrangement, a program in LabView was created. This software saves and graphs the impedance data of each voxel of interest. Our EIT system obtains 208 tetrapolar measurements. However, by the theorem of Geselowitz [42], just 104 measurements are used. 


\subsection{Subjects}

In this research were analyzed 20 healthy males. All subjects were non-smokers with spirometry parameters within normal range. All test were performed between 9 am and noon in a room of pneumology area at sea level with an ambient temperature of $25^{\circ} \mathrm{C}$ and relative humidity of $60 \%$. All volunteers consented to participate in the study, which had been previously approved by the ethics committee of our center.

\subsection{Procedure}

The TIE4sys and pneumotachometer were simultaneously connected to each volunteer. The impedance changes obtained by TIE4sys, using EIT image and all 4-electrodes configurations, and the volume variations obtained by pneumotachometer were analyzed by a parametric correlation test. With this analysis, we can determine the best 4-electrodes configurations.

For each 4-electrodes configuration chosen, 20 calibration equations were obtained. Firstly, we randomly order all volunteers. The sample was divided into two groups. The first (12 subjects) and second one (8 subjects) were called obtaining and validation group, respectively. This procedure was repeated 20 times. In each obtaining group, we used a general equation that allows to adjust the impedance changes into a measurable volume signal, the equation is expressed as following:

$$
\Delta Z=A \times \Delta V
$$

where, $\Delta Z$ is the impedance changes obtained by TIE4sys using 4-electrodes configurations, $\Delta V$ is the volume changes obtained by the pneumotachometer, and $A$ is a proportionality coefficient or calibration coefficient. This is defined in term of different anthropometric parameters [A=(age, weight, height, etc...)].

The tidal volume of each volunteer was recorded at rest 3 times during periods of 30 seconds, with 3minutes rest between measurements. Each respiratory maneuver was registered graphically and numerically. Prior to measure the respiration pattern, we recorded the anthropometric parameters as age, height, weight, and body mass index. We measure chest perimeters at rest, maximum inspiration and expiration. Also, we measure the side, front, back and subscapular skinfold thickness.

\subsection{Statistical analysis}

All data are expressed in terms of means \pm standard deviations values. The Pearson's correlation coefficient was used to select the best 4-electrode configurations. This parameter was set up over 0.500 (p < 0.05). This statistical test was used because volume and impedance measurements showed a normal distribution (Kolmogorov-Smirnov test, $\mathrm{p}<0.005$ ). Once the best 4-electrodes configurations were chosen, the calibration equations were obtained. Each calibration mathematical model was obtained by a multivariate linear regression of anthropometric parameters and the proportionality coefficients (A). This parameter is estimated by the quotient of tidal volume mean value (from pneumotachometer) and the impedance mean value (from TIE4sys).

The comparison between the volume determinations obtained by pneumotachometer and TIE4sys in each validation group was performed by using parametric statistical trials: the Student's t-test for related data, the Levene's test and the Pearson's correlation coefficient (r). In the statistical analysis, it was also used the error (in percentage) of the volume determinations obtained by TIE4sys, using each electrodes configuration, regarding to the measurements obtained by pneumotachometer.

\section{Results}

\subsection{Analysis of 4-electrodes configurations and general calibration model}

The mean values of anthropometric parameters corresponding to the male sample were an age of $27 \pm 7$ year, a height of $1.79 \pm 0.1 \mathrm{~m}$, a weight of $76.8 \pm 12 \mathrm{~kg}$ and a body mass index of $24.1 \pm 3.3 \mathrm{~kg} / \mathrm{m}^{2}$. The thoracic skinfold measurements at front, side, back, and subscapular were $19 \pm 5 \mathrm{~mm}, 19 \pm 9 \mathrm{~mm}, 21 \pm 7 \mathrm{~mm}$ and $22 \pm$ 
$8 \mathrm{~mm}$, respectively. The chest perimeter measurements at rest, maximum inspiration and expiration were $89 \pm$ $6 \mathrm{~cm}, 93 \pm 6 \mathrm{~cm}$ and $87 \pm 6$, respectively.

In each respiratory exercise performed by each volunteer, the impedance changes obtained by TIE4sys, using EIT image and any 4-electrode configurations, and the volume variations obtained by pneumotachometer showed a high correlation $(\mathrm{r}>0.9, \mathrm{p}<0.05)$. The significant Pearson's correlations $(\mathrm{p}<0.05)$ between the impedance determinations obtained by TIE4sys, different 4-electrodes configurations taken from IEITM, and the volume determinations obtained by pneumotachometer in the male sample (M:20) are shown in table 1. Based on our selection criteria $(r>0.500$ with $\mathrm{p}<0.05$ ), the best 4-electrodes configurations were the arrangements of electrodes 3,4 (injection pair) - 11,12 (detection pair) and the electrodes 4,5 (injection pair) 12,13 (detection pair), see figure 1 and 2. The Pearson's correlation determined by EIT image was also significant and fits with our inclusion criteria.

The general mathematical model that describe all calibration equations obtained in this study is expressed as following.

$$
\begin{aligned}
\mathrm{A}=\mathrm{Cte}+\alpha_{1} \times \text { Age } & +\alpha_{2} \times \text { Weight }+\alpha_{3} \times \mathrm{BMI}+\alpha_{4} \times \mathrm{ThP} \text { Insp }+\alpha_{5} \times \mathrm{ThP} \text { Exp }+\alpha_{6} \times \text { ThP_Rest } \\
& +\alpha_{7} \times \text { Front_Sf }+\alpha_{8} \times \text { Back_Sf }+\alpha_{9} \times \text { Average_Sf }+\alpha_{10} \times \mathrm{SS} \_\mathrm{Sf}
\end{aligned}
$$

Where, Cte is the constant term, $\alpha_{i}$ is the constant of each term and BMI is the body mass index. ThP_Insp, Thp_ExP and ThP_Rest are the thoracic perimeters at maximum inspiration, maximum expiration and at rest, respectively. Front_Sf, Back_Sf and SS_Sf are the front, back and subscapular thoracic skinfolds, respectively. Average_Sf is the mean value of front, back and side chest skinfold parameters. All equations are shown in table 2, 3 and 4 .

\subsection{Results obtained by using EIT image}

From the 20 obtained calibration equations, 19 of them involve the subscapular skinfold, 16 the weight, 2 the body mass index (BMI) and 1 the age. All these mathematical models are shown in table 2. The mean value $( \pm \mathrm{SD})$ of the determination coefficients $\left(\mathrm{R}^{2}\right)$ of the 20 calibration equations determined by using EIT image was of $0.943 \pm 0.010$ (see figure 3).

All equations were assessed in their respective validation groups. The volume determinations obtained by TIE4sys, using EIT image, and those obtained by the pneumotachometer, are shown in table 5 . The mean value of Pearson's correlation coefficients of the volume determinations obtained by both monitoring devices was of $0.821 \pm 0.079$ (see table 6). All of them with a p-value less of 0.05 . Just in one group was not evidenced a significant correlation between volume measurements $(r=0.685 ; \mathrm{p}=0.061)$. The error (in terms of percentage) of volume determinations obtained by TIE4sys regarding to the volume measurements obtained by pneumotachometer was of $15 \pm 6 \%$ (see table 5 ). The mean $( \pm S D)$ of t-test's and Levene's p-values determined by volume measurements obtained by TIE4sys and pneumotachometer in all groups was of $0.505 \pm 0.329$ and $0.637 \pm 0.288$, respectively. These results are shown in table 6 .

\subsection{Results obtained by using the configuration $3,4-11,12$}

From the 20 obtained calibration equations, all of them involve the weight, 5 include the chest perimeter at rest (ThP_Rest), 4 the chest perimeter at maximum expiration, 3 the back thoracic skinfold, 1 the mean value of front, back and side thoracic skinfolds and 1 the chest perimeter at maximum inspiration. All this mathematical models are shown in table 3 . The mean value $( \pm S D)$ of the determination coefficients $\left(\mathrm{R}^{2}\right)$ of the 20 calibration equations determined by using the configurations of electrodes 3-4 and 11-12 was of $0.848 \pm$ 0.062 (see figure 3).

All calibration models were validated in their respective validation groups. The volume determinations obtained by TIE4sys, using configuration of electrodes 3-4 and 11-12, and those obtained by the pneumotachometer corresponding to each group are shown in table 5. The mean value of Pearson's correlation coefficients of the volume determinations obtained by TIE4sys and pneumotachometer was of $0.816 \pm 0.070$ (see table 6). All of them with a p-value less of 0.05 . Similar to the latter analysis, just in one group was not evidenced a significant correlation between volume measurements taken from both monitoring devices $(\mathrm{r}=0.664 ; \mathrm{p}=$ 
0.070). The error (in terms of percentage) of volume determinations obtained by TIE4sys regarding to the volume measurements obtained by pneumotachometer (gold standard) was of $16 \pm 4 \%$ (see table 5 ). The mean $( \pm \mathrm{SD})$ of t-test's and Levene's p-values determined by volume measurements obtained by TIE4sys and pneumotachometer in all groups was of $0.252 \pm 0.292$ and $0.529 \pm 0.287$, respectively. These results are shown in table 6 .

\subsection{Results obtained by using the configuration 4,5-12,13}

From the 20 obtained calibration models, 16 of them involve the weight, 2 the body mass index, 1 the age, 1 the front thoracic skinfold, 1 the side thoracic skinfold and 1 the subscapular skinfold. All these equations are shown in table 4. The mean value $( \pm S D)$ of the determination coefficients $\left(R^{2}\right)$ of the 20 calibration equations determined by using the arrangement of electrodes $4-5$ and $12-13$ was of $0.690 \pm 0.122$ (figure 3 ).

All calibration equations were assessed in their respective validation groups. The volume determinations obtained by TIE4sys, using configuration 4-5 and 12-13, and those obtained by the pneumotachometer, corresponding to each group are shown in table 5. The mean value of Pearson's coefficients of the volume determinations obtained by TIE4sys and pneumotachometer was of $0.500 \pm 0.405$, showing a p-value of $0.346 \pm 0.351$ (see table 6). In this analysis, 9 from the 20 studied groups evidence a significant correlations between the volume measurements obtained by both devices. The remainder did not evidence a significant correlation. The error (in terms of percentage) of volume determinations obtained by TIE4sys regarding to the volume measurements obtained by pneumotachometer (gold standard) was of $43 \pm 41 \%$ (see table 5 ). The mean of t-test's and Levene's p-values determined by volume measurements obtained by TIE4sys and pneumotachometer in all groups was of $0.432 \pm 0.322$ and $0.420 \pm 0.317$, respectively. These results are shown in table 6.

\section{Discussion}

In previous works, our research group have obtained a set of calibration equations for being used by our EIT system (TIE4sys). The impedance changes were adjusted and transformed into a measurable volume signal. In these cases, the EIT 16-electrodes configuration was used. The results obtained in healthy males evidenced that the mathematical adjustment of calibration equations was roughly $\mathrm{R}^{2}=0.9(\mathrm{p}<0.05)$. Therefore, the volume determinations obtained by EIT were acceptable in order to monitor respiratory pattern. However, EIT systems are expensive for been acquired by any specialist. For this reason, we decided to use tetrapolar impedance measurements because these kind of determinations can be recreated by any cheap impedance equipment. Our research group analyzed the impedance changes taken from the IEITM, using only the 4-electrodes configurations, and the volume measurements obtained by the gold standard. The first objective of this research was to find out the optimal position of electrodes to monitor the ventilatory pattern. And the second one was to obtain a set of calibration mathematical models in order to adjust the tetrapolar impedance changes taken from IEITM and transformed it into a measurable volume signal.

To accomplish the first objective, the tetrapolar impedance changes taken from IEITM (Figure 1) and volume determinations obtained by pneumotachometer were analyzed by the Pearson's correlation test. By this statistical test, the best 4-electrodes configurations were selected. It was evidenced that only two configurations shown a correlation over $r>0.5(p<0.5)$. The first one is determined by the pair $3-4$, used as current injector, and the pair 11-12, used as voltage detector (Figure 2). The second one is determined by the pair 4-5, used as injector, and the pair 12-13, used as detector (Figure 2). Whole EIT image was selected too. We consider that these two electrodes configuration were significant because of they provide more information about the respiration component. The injector pairs 3-4 and 4-5 are placed at the right side of thorax. The right lung is bigger than the left one because it has 3 lobes while the left has only 2 . This is due to the space that heart occupies [43].

Now, to achieve the second objective, we have obtained and assessed 20 calibration equations for each selected electrodes configuration. It was evidenced that variation of the mathematical adjustment of calibration equations determined by EIT image was of 1\%. However, the variation of the adjustment of those equations 
determined by the configuration of electrodes 3-4 and $11-12$ and $4-5$ and $12-13$ was of $7 \%$ and $18 \%$, respectively. The low variability of the equations determined by EIT image was due to the fact that all 104 tetrapolar impedance measurements are used [44]. The variability of those equations determined by the configuration of electrodes 3-4 and 11-12 may be compared with the obtained by the EIT image despite of using only one tetrapolar configuration. The high variability of the mathematical adjustment of those equations determined by the configuration 4-5 and 12-13 was due to a low correlation between the proportionality coefficients (A) and the anthropometrical data corresponding to each obtaining group.

Weight was the most involved parameter in almost all calibration equations. This fact could be explained because the electrical current transfer depend on the resistance of whole human body mass. Each human tissue have different impedance index [45]. The tissue with the larger impedance value is fat. This factor makes difficult the calibration equation obtaining.

Once the calibration equations were obtained, all of them were used by TIE4sys in order to adjust and transform the impedance changes into a measurable volume signal. The statistical comparison of volume determinations evidenced that the use of EIT image and the configuration of electrodes 3-4 and 11-12 are exchangeable for respiration monitoring. Probably, the configuration 3-4 and 11-12 is a good option because the position where the electrodes were placed was in a thoracic zone with less fat. Then, the electrical current passed through the thoracic muscles with facility and the impedance changes reflects easily the respiratory component. However, the correlations determined by the configuration 4-5 and 12-13 were not so good. Probably, the electrodes were placed in a zone with fat or it is possible that the impedance changes reflect also the cardiac component.

The comparison of errors of volume determinations obtained by TIE4sys, using the EIT image and both configurations of electrodes, regarding to volume determinations obtained by pneumotachometer is shown in table 5. In there, it is evident that the errors determined by the EIT image and the configuration of electrodes 311 and 11-12 are similar. The errors determined by both electrodes configurations did not shown statistically significant differences. Now, comparing these errors with those obtained by the configuration 4-5 and 12-13, it evidenced a significant differences. It was because of two groups of validation showed errors over $150 \%$. If we take off the off layers, the error determined by this electrodes configuration is of $30 \pm 3 \%$. However, this value is too large to monitor the respiration.

In this study, all volume determinations were restricted in a small range $(400-700 \mathrm{ml})$. So, the conclusions must be restricted to this volume range. In future studies, we need to improve the calibration equations by increasing the sample and assessing new anthropometric parameters.

\section{Conclusions}

The best mathematical adjustments of calibration equations were determined by using the EIT image and the configuration of electrodes 3-4 and 11-12. The most significant parameter involved in all of them was the weight. This confirm that transfer of electrical current depends on the resistance of whole human body mass. By using these equations, the percentage error of volume determinations obtained by TIE4sys was low enough to monitor de respiratory pattern. In the case of EIT image, the impedance variations are determined by the contribution of different impedance measurements taken around the thorax. So, the total impedance change includes different respiratory components from both lungs. However, the impedance changes taken from the configuration 3-4 and 11-12 was comparable with EIT image. So, the position of these 4-electrodes configuration was ideal to monitor breathing pattern.

\section{Acknowledgments}

Dirección de Investigación y Posgrado (DAIP) (FO-DAI-05), Universidad de Guanajuato for financial support and CONACYT (postdoctoral fellowship) to Marco Balleza. 


\section{References}

[1] Sanchis J., Díez-Betoret L., Canet J., Casan P. Pneumotachographic recording of ventilatory pattern. En Benito S. and Net A (Editores), Update in intensive care and emergency medicine 13: Pulmonary function in mechanically ventilated patients. Berlin-Heidelberg: Springer-Verlag. (1991) pp:9-22.

[2] Serra Gabriel X. Anatomía básica del aparato respiratorio. En María Rosa Serra Gabriel, Josefina Díaz Petit y María Luisa de Sande Carril (Comp), Fisioterapia en neumología, sistema respiratorio y aparato cardiovascular Barcelona: Elsevier (2005) pp 281-293.

[3] Gilbert, R., Auchincloss J. H., Brodsky J., Boden W. Changes in tidal volume, frequency and ventilation induced by their measurement. J Appl Physiol, (1972) 33:252-254.

[4] Askanazi J., Silverberg P. A., Foster R. J., Hyman A. I. Effects of respiratory apparatous on breathing pattern. J Appl Physiol, (1980) 48:577-580.

[5] Perez, W. and Tobin M. J. Separation of factor responsible for change in breathing pattern induced by instrumentation. J Appl Physiol, (1985) 59:1515-1520.

[6] Paek D. and McCool D. Breathing patterns during varied activities. J Appl Physiol, (1992) 73:887-893.

[7] Germán Peces-Barba, Joan Albert Barberà, Àlvar Agustí, Ciro Casanova, Alejandro Casas, José Luis Izquierdo, José Jardim, Victorina López Varela, Eduard Monsó, Teodoro Montemayor, José Luis Viejo. Joint guidelines of the Spanish Society of Pulmonology and Thoracic Surgery (SEPAR) and the Latin American Thoracic Society (ALAT). Arch Bronconeumol. 42 (2008) 271-281.

[8] Whyte K. F., Gugger M., Gould G. A., Molloy J., Wraith P. K., Douglas N. J. Accuracy of respiratory inductive plethysmograph in measuring tidal volume during sleep. J Appl Physiol, (1991) 71:1866-1871

[9] Stick S. M., Ellis E., LeSouëf P. N., Sly P. D. Validation of respiratory inductance plethysmography ("Respitrace") for the measurement of tidal breathing parameters in newborns. Pediatric Pulmonology, (1992) 14(3):187-191.

[10] Cohen K. P., Ladd W. M., Beams, D. M., Sheers W. S., Radwin R. G., Tompkins W. J., Webster J. G. Comparison of impedance and inductance ventilation sensors on adults during breathing, motion and simulated airway obstruction. IEEE Transactions on Biomedical Engineering, (1997) 44(7):555-566.

[11] Durán, J., Esnaola, S., Rubio, R., \& Iztueta, Á. Obstructive sleep apnea-hypopnea and related clinical features in a population-based sample of subjects aged 30 to 70 yr. American journal of respiratory and critical care medicine, (2001) 163(3), 685-689

[12] Giaever I. and Keese C. R. A morphological biosensor for mammalian cells. Nature (1993) 366:591-592.

[13] Pethig R. and Kell B. The passive electrical properties of biological systems: their significance in physiology, biophysics and biotechnology. Phys Med Biol. (1987) 32:933-970.

[14] Pethig R., Burt J. P. H., Parton A., Rizvi N., Talary M. S., and Tame J. A. Development of biofactory-on-a-chip technology using excimer laser micromachining. J. Micromech. Microeng. (1998) 8:57-63.

[15] Kachel V., Electrical resistance pulse sizing: Coulter sizing. In: M. R. Melamed, T. Lindmo, and M. L. Mendelsohn, eds., Flow Cytometry and Sorting. New York:Wiley-Liss Inc., (1990) pp. 45-80.

[16] Lukaski H.C., Johnson P.E., Bolonchuk W.W. and Lykken G.I. Assessment of fat-free mass using bioelectrical impedance measurements of human body. Am. J. Clin. Nutr. (1985) 41(4): 810 - 817.

[17] Lukaski H.C., Bolonchuk W.W., Hall C.B. and Siders W.A. Validation of tetrapolar bioelectrical impedance method to assess human body composition. Journal of Applied Physiology (1986) 60(4): 1327 - 1332.

[18] Lukaski H.C. Methods for assessment of human body composition: traditional and new. Am. J. Clin. Nutr. (1987) 46(4): $537-556$.

[19] Foster K. R. and Schwan H. P. (1989). Dielectric properties of tissues and biological materials: a critical review. Critical Reviews in Biomedical Engineering. 17(1):25-104.

[20] Kubicek W.G., Patterson R.P., Witsoe D.A. Impedance cardiography as a noninvasive method of monitoring cardiac function and other parameters of the cardiovascular system. Annals of New York Academy of Sciences (1970) 170: $724-732$.

[21] Kaupinen P. K., Hyttinen J. A., and Malmivuo J. A., Sensitivity distributions of impedance cardiography using band and spot electrodes analysed by a 3-D computer model. Ann. Biomed. Eng. (1998) 26:694-702.

[22] Cinca J., Ramos J., García M. A., Bragos R., Bayés-Genis A., Salazar Y., Bordes R., Mirabet S., Padró J. M., Picart J. G., Viñolas X., Rosell-Ferrer J. Changes in myocardial electrical impedance in human heart graft rejection. Eur J Heart Fail, (2008) 10:594-600.

[23] Piccoli A. Bioelectric impedance measurements for fluid status assessment. Contributions to Nephrology, (2010) 164:143-152.

[24] Houtveen, J. H., Groot, P. F., \& de Geus, E. J. Validation of the thoracic impedance derived respiratory signal using multilevel analysis. International Journal of Psychophysiology, (2006) 59(2), 97-106. 
[25] Roberts, K., Srinivasan, V., Niles, D. E., Eilevstjønn, J., Tyler, L., Boyle, L., ... \& Nadkarni, V.. Does change in thoracic impedance measured via defibrillator electrode pads accurately detect ventilation breaths in children?. Resuscitation, (2010) 81(11), 1544-1549.

[26] B. H. Brown, A. D. Seagar, The Sheffield data collection system, Clin. Phys. Physiol. Meas. 8 (1987) Suppl. A: 9197.

[27] B. H. Brown, Electrical impedance tomography (EIT): a review, Journal of Medical Engineering \& Technology. 27 (2003) 97-108.

[28] M. Bodenstein, M. David, K. Markstaller, Principles of electrical impedance tomography and its clinical application, Critical Care Medicine. 37(2) (2009) 713-724.

[29] P.W. Kunst, A. Vonk Noordegraaf, E. Raaijmakers, J. Bakker, A. B. Groeneveld, P. E. Postmus, P. M. de Vries, Electrical impedance tomography in the assessment of extravascular lung water in noncardiogenic acute respiratory failure, Chest. 116 (1999) 1695-1702.

[30] M. Arad, S. Zlochiver, T. Davidson, Y. Shoenfeld, A. Adunsky, S. Abboud, The detection of pleural effusion using parametric EIT technique, Physiol Meas. 30 (2009) 421-428.

[31] B. Grychtol, G. K. Wolf, J. H. Arnold, Differences in regional pulmonary pressure impedance curves before and after lung injury assessed with a novel algorithm, Physiol Meas. 30 (2009)137-148.

[32] I. Frerichs, P. A. Dargaville, P. C. Rimensberger, Regional respiratory inflation and deflation pressure-volume curves determined by electrical impedance tomography, Physiol. Meas. 34 (2013) 567-577

[33] Balleza, M., Calaf, N., Feixas, T., González, M., Antón, D., Riu, P. J., \& Casan, P. Measuring breathing pattern in patients with chronic obstructive pulmonary disease by electrical impedance tomography. Archivos de Bronconeumología (2009), 45(7), 320-324.

[34] Balleza-Ordaz, M., Perez-Alday, E., Vargas-Luna, M., \& Riu, J. P. Tidal volume monitoring by electrical impedance tomography (EIT) using different regions of interest (ROI): Calibration equations. Biomedical Signal Processing and Control, (2015)18, 102-109.

[35] B. De Lema, P. Casan, P.J. Riu, Electrical Impedance Tomography: standardizing in the procedure in pneumology. Arch Bronconeumol. 42 (2006) 299-301.

[36] Casas, O. Contribución a la obtención de imágenes paramétricas en tomografía de impedancia eléctrica para la caracterización de tejidos biológicos. Tesis Doctoral, UniversitatPolitècnica de Catalunya, Barcelona, (1998).

[37] Fontova A. Desenvolupament d'un mòdul de comunicacions Ethernet per a un sistema de TIE. Projecte fi de Carrera. E.T.S.E.T.B. UniversitatPolitècnica de Catalunya (2004).

[38] Fornos Herrando J. Estimació del Patró Ventilatori mitjançant Tomografía d’Impedància Elèctrica. Projecte fi de Carrera. E.T.S.E.T.B. UniversitatPolitècnica de Catalunya (2006).

[39] Serrano R. E., De Lema B., Casas O., Feixas T., Calaf N., Camacho V., Carrio I., Casan P., and Riu J.P. Use of electrical impedance tomography (TIE) for the assessment of unilateral pulmonary function. Physiological Measurements (2002) 23:211-220.

[40] Muller J. L., Siltanen S., Isaacson D. A direct reconstruction algorithm for electrical impedance tomography. IEEE Trans Med Imaging, (2002) 21:555-559.

[41] Santosa F. and Vogelius M. A backprojection algorithm for electrical impedance imaging. University of Maryland Technical note BN-1081, (1988) pp:1-33.

[42] Geselowitz D. B. An application of electrocardiographic leas theory to impedance plethysmography. IEEE Trans Biomed Eng. (1971) 18:38-41.

[43] G. J. Tortora, B. H. Derrickson. Principles of anatomy and physiology, $14^{\text {th }}$ ed., Wiley, December 2014.

[44] Serrano R. E., De Lema B., Casas O., Feixas T., Calaf N., Camacho V., Carrio I., Casan P., and Riu J.P. Use of electrical impedance tomography (TIE) for the assessment of unilateral pulmonary function. Physiological Measurements (2002) 23:211-220.

[45] S. Grimnes, Ø. G. Martinsen. Bioimpedance \& Bioelectricity, $2^{\text {nd }}$ ed. Elsevier, 2008. 


\section{List of images}

Figure 1. Spatial position of electrodes placed around the thorax at sixth intercostal space.

Figure 2. Impedance EIT matrix (IEITM) used for EIT image reconstruction. In the picture letter A depicts the configurations of 2 electrodes; letter B depicts the configurations of 3 electrodes and letter $\mathrm{C}$ depicts the configurations of 4 electrodes. This latter is configuration of interest.

Figure 3. Mean ( \pm SD) values of the determination coefficients of the 20 calibration equations determined by each electrodes configuration. EIT image is the configuration determined by the use of 16-electrode configuration. Config 3.11 is the configuration determined by the electrodes 3-4 (current injectors) and 11-12 (voltage detectors). Config 4.12 is the configuration determined by the electrodes 4-5 (current injectors) and 12-13 (voltage detectors). These configurations are shown in figure 2. 


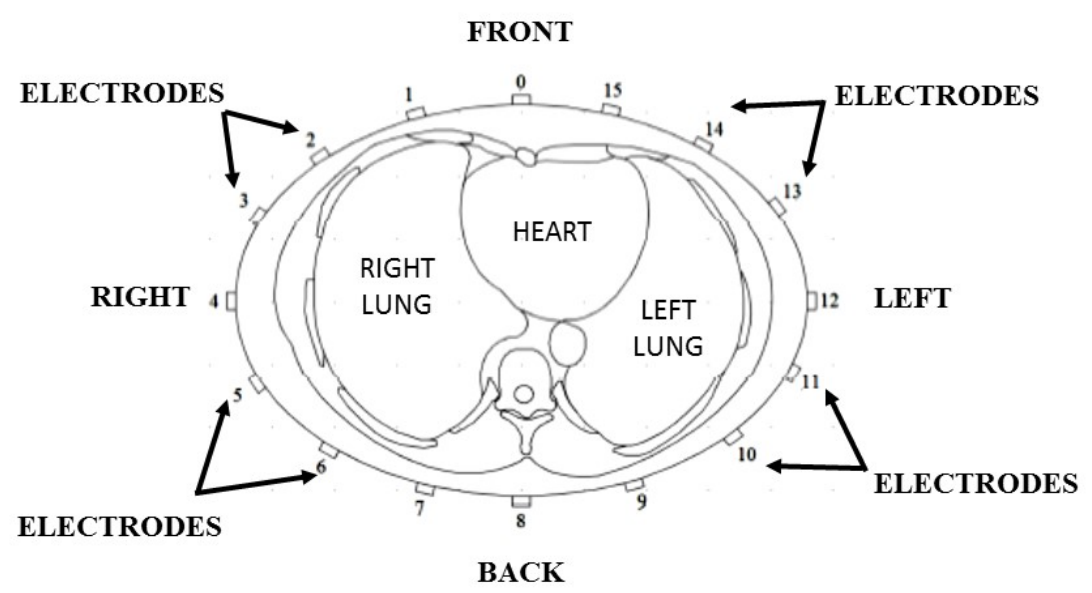

Figure 1. Spatial position of electrodes placed around the thorax at sixth intercostal space. 


\section{Pair electrodes detection}

\begin{tabular}{|c|c|c|c|c|c|c|c|c|c|c|c|c|c|c|c|c|}
\hline & 0,1 & 1,2 & 2,3 & 3,4 & 4,5 & 5,6 & 6,7 & 7,8 & 8,9 & 9,10 & 10,11 & 11,12 & 12,13 & 13,14 & 14,15 & 15,0 \\
\hline 0,1 & A & B & $\mathrm{C}$ & $\mathrm{C}$ & $\mathrm{C}$ & $\mathrm{C}$ & $\mathrm{C}$ & $\mathrm{C}$ & $\mathrm{C}$ & $\mathrm{C}$ & C & C & C & C & C & $\mathrm{C}$ \\
\hline 1,2 & B & A & B & $\mathrm{C}$ & $\mathrm{C}$ & $\mathrm{C}$ & $\mathrm{C}$ & $\mathrm{C}$ & $\mathrm{C}$ & $\mathrm{C}$ & $\mathrm{C}$ & $\mathrm{C}$ & $\mathrm{C}$ & $\mathrm{C}$ & $\mathrm{C}$ & $\mathrm{C}$ \\
\hline 2,3 & $\mathrm{C}$ & B & A & B & $\mathrm{C}$ & $\mathrm{C}$ & $\mathrm{C}$ & $\mathrm{C}$ & $\mathrm{C}$ & $\mathrm{C}$ & $\mathrm{C}$ & $\mathrm{C}$ & $\mathrm{C}$ & $\mathrm{C}$ & $\mathrm{C}$ & $\mathrm{C}$ \\
\hline 3,4 & $\mathrm{C}$ & $\mathrm{C}$ & B & A & B & $\mathrm{C}$ & $\mathrm{C}$ & $\mathrm{C}$ & $\mathrm{C}$ & $\mathrm{C}$ & $\mathrm{C}$ & $\mathrm{C}$ & $\mathrm{C}$ & $\mathrm{C}$ & $\mathrm{C}$ & $\mathrm{C}$ \\
\hline 4,5 & $\mathrm{C}$ & $\mathrm{C}$ & $\mathrm{C}$ & B & A & B & $\mathrm{C}$ & $\mathrm{C}$ & $\mathrm{C}$ & $\mathrm{C}$ & $\mathrm{C}$ & $\mathrm{C}$ & $\mathrm{C}$ & $\mathrm{C}$ & $\mathrm{C}$ & $\mathrm{C}$ \\
\hline 5,6 & $\mathrm{C}$ & $\mathrm{C}$ & $\mathrm{C}$ & $\mathrm{C}$ & B & A & B & $\mathrm{C}$ & $\mathrm{C}$ & $\mathrm{C}$ & $\mathrm{C}$ & $\mathrm{C}$ & $\mathrm{C}$ & $\mathrm{C}$ & $\mathrm{C}$ & $\mathrm{C}$ \\
\hline 6,7 & $\mathrm{C}$ & $\mathrm{C}$ & $\mathrm{C}$ & $\mathrm{C}$ & $\mathrm{C}$ & B & A & B & $\mathrm{C}$ & $\mathrm{C}$ & $\mathrm{C}$ & $\mathrm{C}$ & $\mathrm{C}$ & $\mathrm{C}$ & $\mathrm{C}$ & $\mathrm{C}$ \\
\hline 7,8 & $\mathrm{C}$ & $\mathrm{C}$ & $\mathrm{C}$ & $\mathrm{C}$ & C & $\mathrm{C}$ & B & A & B & $\mathrm{C}$ & $\mathrm{C}$ & $\mathrm{C}$ & $\mathrm{C}$ & $\mathrm{C}$ & $\mathrm{C}$ & $\mathrm{C}$ \\
\hline 8,9 & $\mathrm{C}$ & $\mathrm{C}$ & $\mathrm{C}$ & $\mathrm{C}$ & $\mathrm{C}$ & $\mathrm{C}$ & $\mathrm{C}$ & B & A & B & $\mathrm{C}$ & $\mathrm{C}$ & $\mathrm{C}$ & $\mathrm{C}$ & $\mathrm{C}$ & $\mathrm{C}$ \\
\hline 9,10 & $\mathrm{C}$ & $\mathrm{C}$ & $\mathrm{C}$ & $\mathrm{C}$ & $\mathrm{C}$ & $\mathrm{C}$ & $\mathrm{C}$ & $\mathrm{C}$ & B & A & B & $\mathrm{C}$ & $\mathrm{C}$ & $\mathrm{C}$ & $\mathrm{C}$ & $\mathrm{C}$ \\
\hline 10,11 & $\mathrm{C}$ & $\mathrm{C}$ & $\mathrm{C}$ & $\mathrm{C}$ & $\mathrm{C}$ & $\mathrm{C}$ & $\mathrm{C}$ & $\mathrm{C}$ & $\mathrm{C}$ & B & A & B & $\mathrm{C}$ & $\mathrm{C}$ & $\mathrm{C}$ & $\mathrm{C}$ \\
\hline 11,12 & $\mathrm{C}$ & $\mathrm{C}$ & $\mathrm{C}$ & $\mathrm{C}$ & $\mathrm{C}$ & $\mathrm{C}$ & $\mathrm{C}$ & $\mathrm{C}$ & $\mathrm{C}$ & $\mathrm{C}$ & B & $\mathrm{A}$ & B & $\mathrm{C}$ & $\mathrm{C}$ & $\mathrm{C}$ \\
\hline 12,13 & $\mathrm{C}$ & $\mathrm{C}$ & $\mathrm{C}$ & $\mathrm{C}$ & $\mathrm{C}$ & $\mathrm{C}$ & $\mathrm{C}$ & $\mathrm{C}$ & $\mathrm{C}$ & $\mathrm{C}$ & $\mathrm{C}$ & B & A & B & $\mathrm{C}$ & $\mathrm{C}$ \\
\hline 13,14 & $\mathrm{C}$ & $\mathrm{C}$ & $\mathrm{C}$ & $\mathrm{C}$ & $\mathrm{C}$ & $\mathrm{C}$ & $\mathrm{C}$ & $\mathrm{C}$ & $\mathrm{C}$ & $\mathrm{C}$ & $\mathrm{C}$ & $\mathrm{C}$ & B & A & B & $\mathrm{C}$ \\
\hline 14,15 & $\mathrm{C}$ & $\mathrm{C}$ & $\mathrm{C}$ & $\mathrm{C}$ & $\mathrm{C}$ & $\mathrm{C}$ & $\mathrm{C}$ & $\mathrm{C}$ & $\mathrm{C}$ & $\mathrm{C}$ & $\mathrm{C}$ & $\mathrm{C}$ & $\mathrm{C}$ & B & $\mathrm{A}$ & B \\
\hline 15,0 & $\mathrm{C}$ & $\mathrm{C}$ & $\mathrm{C}$ & $\mathrm{C}$ & $\mathrm{C}$ & $\mathrm{C}$ & $\mathrm{C}$ & $\mathrm{C}$ & $\mathrm{C}$ & $\mathrm{C}$ & $\mathrm{C}$ & $\mathrm{C}$ & $\mathrm{C}$ & $\mathrm{C}$ & B & A \\
\hline
\end{tabular}

Figure 2. Impedance EIT matrix (IEITM) used for EIT image reconstruction. In the picture letter A depicts the configurations of 2 electrodes; letter B depicts the configurations of 3 electrodes and letter $\mathrm{C}$ depicts the configurations of 4 electrodes. This latter is configuration of interest. 


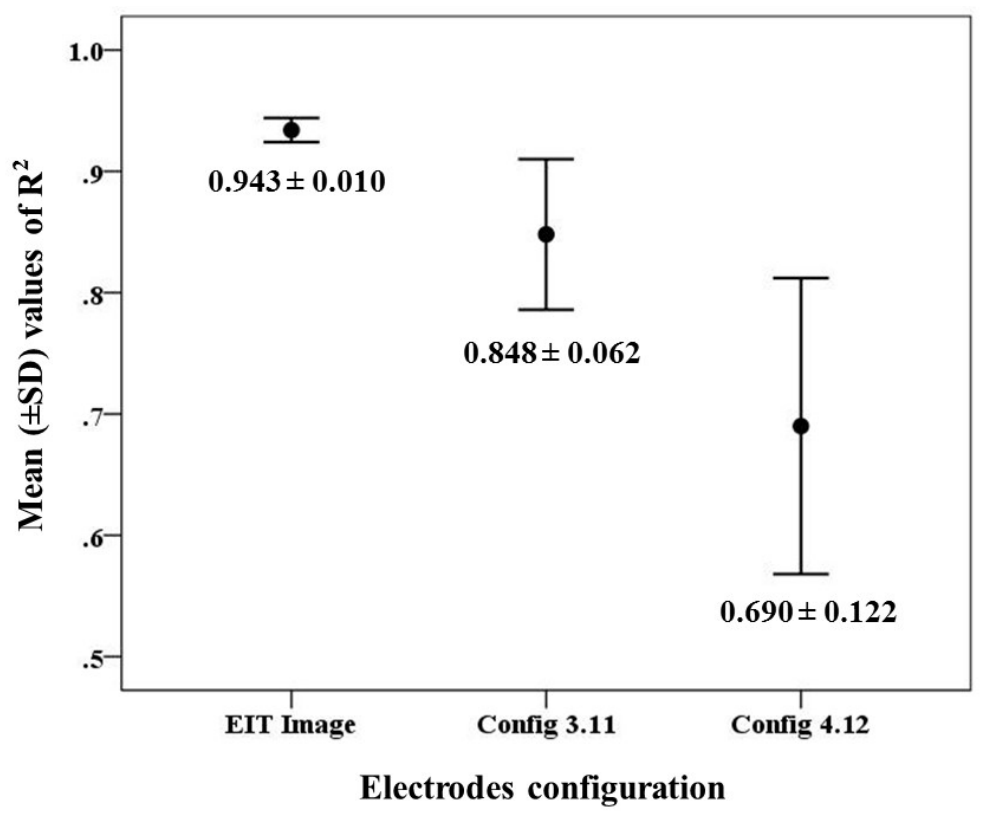

Figure 3. Mean $( \pm S D$ ) values of the determination coefficients of the 20 calibration equations determined by each electrodes configuration. EIT image is the configuration determined by the use of 16-electrode configuration. Config 3.11 is the configuration determined by the electrodes 3-4 (current injectors) and 11-12 (voltage detectors). Config 4.12 is the configuration determined by the electrodes 4-5 (current injectors) and 12-13 (voltage detectors). These configurations are shown in figure 2. 


\section{List of tables}

Table 1. Significant Pearson's correlations between impedance determinations obtained by TIE4sys, using EIT image (16-electrodes arrangement) and different 4-electrodes configurations, and volume determinations obtained by pneumotachometer in the sample of volunteers (M:20).

Table 2. Coefficients of calibration equations determined by EIT image.

Table 3. Coefficients of calibration equations determined by the configuration of electrodes 3-4 and 1112. This configuration was taken from the main impedance matrix (IEITM)

Table 4. Coefficients of calibration equations determined by the configuration of electrodes 4-5 and 1213. This configuration was taken from the main impedance matrix (IEITM)

Table 5. Volume determinations differences obtained by TIE4sys, using the 3 configurations of electrodes (EIT image, 3,4-11,12 and 4,5-12,13 electrodes configurations), and those obtained by the pneumotachometer (gold standard). The differences are expressed as percentage (\%).

Table 6. Analysis of volume measurements obtained by pneumotachometer and TIE4sys, using 1) EIT image, 2) 3.11 electrodes configuration and 2) 4.12 electrodes configuration. 
Table 1. Significant Pearson's correlations between impedance determinations obtained by TIE4sys, using EIT image (16-electrodes arrangement) and different 4-electrodes configurations, and volume determinations obtained by pneumotachometer in the sample of volunteers (M:20).

\begin{tabular}{|c|c|}
\hline $\begin{array}{c}\text { Electrodes } \\
\text { configuration }\end{array}$ & $\begin{array}{c}\text { Pearson's coefficient } \\
\text { r (p-value) }\end{array}$ \\
\hline 4-electrodes: 1,2-3,4 & $0.467(0.038)$ \\
\hline 4-electrodes: 3,4-11,12* & $0.568(0.009)$ \\
\hline 4-electrodes: 4,5-9,10 & $0.444(0.050)$ \\
\hline 4-electrodes: 4,5-12,13* & $0.546(0.013)$ \\
\hline 4-electrodes: 12,13-8,9 & $0.488(0.029)$ \\
\hline 16-electrodes (EIT Image) & $0.578(0.008)$ \\
\hline
\end{tabular}

${ }^{(*)}$ Selected electrode configurations. The criteria selection was to obtain a Pearson's correlation coefficient over $0.500(\mathrm{p}<0.05)$. 
Table 2. Coefficients of calibration equations determined by using 16-electrodes arrangement.

\begin{tabular}{|c|c|c|c|c|c|c|}
\hline & Cte $^{1}$ & $\begin{array}{l}\text { Age } \\
{ }^{*} \alpha_{1}\end{array}$ & $\begin{array}{l}\text { Weight } \\
{ }^{*} \alpha_{2}\end{array}$ & $\begin{array}{l}\mathbf{B M I}^{2} \\
{ }^{*} \alpha_{3}\end{array}$ & $\begin{array}{l}\text { SS_Sf } \\
{ }^{*} \alpha_{10}\end{array}$ & $\begin{array}{l}\text { C.D. }{ }^{3} \\
\left(\mathbf{R}^{2}\right)\end{array}$ \\
\hline 1 & 2778 & & -14.0 & & -28.0 & 0.935 \\
\hline 2 & 2711 & & -11.0 & & -35.0 & 0.943 \\
\hline 3 & 2519 & & $\begin{array}{l}-9.1 \\
\end{array}$ & & -33.0 & 0.932 \\
\hline 4 & 2875 & & -15.0 & & -29.0 & 0.948 \\
\hline 5 & 2942 & & -15.5 & & -28.0 & 0.955 \\
\hline 6 & 2835 & & -12.1 & & -34.0 & 0.931 \\
\hline 7 & 2733 & & $\begin{array}{l}-10.8 \\
\end{array}$ & & -35.6 & 0.946 \\
\hline 8 & 1335 & 32.8 & & & -48.0 & 0.954 \\
\hline 9 & 2907 & & -15.1 & & -30.3 & 0.951 \\
\hline 10 & 2684 & & -10.8 & & -34.1 & 0.935 \\
\hline 11 & 2933 & & -14.6 & & -31.4 & 0.953 \\
\hline 12 & 2758 & & & -45.6 & -24.4 & 0.932 \\
\hline 13 & 2944 & & & & $\begin{array}{l}-31.1 \\
\end{array}$ & 0.951 \\
\hline 14 & 2317 & & & & -52.1 & 0.937 \\
\hline 15 & 3499 & & $\begin{array}{l}-9.8 \\
\end{array}$ & -68.9 & & 0.939 \\
\hline 16 & 3070 & & $\begin{array}{l}-17.5 \\
\end{array}$ & & $\begin{array}{l}-27.8 \\
\end{array}$ & 0.965 \\
\hline 17 & 2608 & & -12.2 & & -27.9 & 0.937 \\
\hline 18 & 2576 & & -9.9 & & -32.9 & 0.939 \\
\hline 19 & 2609 & & -11.1 & & -29.4 & 0.931 \\
\hline 20 & 2523 & & -8.4 & & -35.2 & 0.944 \\
\hline
\end{tabular}

${ }^{1}$ Constant term of each equation.

${ }^{2}$ Body mass index

${ }^{3}$ Coefficient of determination.

All values shown a p-value $<0.05$

${ }^{*} \alpha_{i}$ is the constant of each term.

NOTE: the remainder of coefficients of equation (2) are not expressed in this table due to the value of them is zero. 
Table 3. Coefficients of calibration equations determined by the configuration of electrodes 3-4 and 1112. This configuration was taken from the main impedance matrix (IEITM)

\begin{tabular}{|c|c|c|c|c|c|c|c|c|}
\hline & Cte $^{1}$ & $\begin{array}{l}\text { Weight } \\
{ }^{*} \alpha_{2}\end{array}$ & $\begin{array}{c}\text { ThP_Insp }{ }^{2} \\
{ }^{*} \alpha_{4}\end{array}$ & $\begin{array}{c}\text { ThP_Exp }{ }^{3} \\
{ }^{*} \alpha_{5}\end{array}$ & $\begin{array}{c}\text { ThP_Rest }^{4} \\
{ }^{*} \alpha_{6}\end{array}$ & $\begin{array}{c}\text { Back_Sf }{ }^{5} \\
{ }^{*} \alpha_{8}\end{array}$ & $\begin{array}{c}\text { Average_Sf } \\
{ }^{*} \alpha_{9} \\
\end{array}$ & $\begin{array}{l}\text { C.D. }{ }^{7} \\
\left(\mathbf{R}^{2}\right)\end{array}$ \\
\hline 1 & 221 & -2.0 & & & & & & 0.814 \\
\hline 2 & 133 & -2.8 & & 1.7 & & & & 0.854 \\
\hline 3 & 230 & -2.1 & & & & & & 0.774 \\
\hline 4 & 91 & -2.8 & 2.1 & & & & & 0.894 \\
\hline 5 & 227 & -2.0 & & & & & & 0.741 \\
\hline 6 & 145 & -2.9 & & 1.8 & & & & 0.883 \\
\hline 7 & 218 & -2.0 & & & & & & 0.802 \\
\hline 8 & 274 & -3.3 & & & & 2.4 & & 0.896 \\
\hline 9 & 58 & -3.1 & & & 2.8 & & & 0.836 \\
\hline 10 & 117 & -2.2 & & & 1.3 & & & 0.921 \\
\hline 11 & 140 & -2.9 & & 1.8 & & & & 0.852 \\
\hline 12 & 237 & -2.1 & & & & & & 0.683 \\
\hline 13 & 268 & -3.1 & & & & 2.0 & & 0.874 \\
\hline 14 & 120 & -2.7 & & & 1.7 & & & 0.880 \\
\hline 15 & 245 & -2.2 & & & & & & 0.837 \\
\hline 16 & 268 & -3.0 & & & & 1.7 & & 0.862 \\
\hline 17 & 222 & -2.5 & & & & & 1.9 & 0.935 \\
\hline 18 & 122 & -2.7 & & 1.8 & & & & 0.845 \\
\hline 19 & 116 & -2.6 & & & 1.7 & & & 0.912 \\
\hline 20 & 49 & -3.3 & & & 3.1 & & & 0.869 \\
\hline
\end{tabular}

${ }^{1}$ Constant term of each equation.

2 Thoracic perimeter at maximum inspiration.

${ }^{3}$ Thoracic perimeter at maximum expiration.

4 Thoracic perimeter at rest.

${ }^{5}$ Back thoracic skinfold.

${ }^{6}$ Mean value of back, front and side chest skinfolds parameters.

${ }^{7}$ Coefficient of determination. All p-values were less than 0.05

${ }^{*} \alpha_{i}$ is the constant of each term.

NOTE: the remainder of coefficients of equation (2) are not expressed in this table due to the value of them is zero. 
Table 4. Coefficients of calibration equations determined by the configuration of electrodes 4-5 and 1213. This configuration was taken from the main impedance matrix (IEITM)

\begin{tabular}{|c|c|c|c|c|c|c|c|c|}
\hline & Cte $^{1}$ & $\begin{array}{l}\text { Age } \\
{ }^{*} \alpha_{1}\end{array}$ & $\begin{array}{l}\text { Weight } \\
{ }^{*} \alpha_{2}\end{array}$ & $\begin{array}{l}\text { BMI }^{2} \\
{ }^{*} \alpha_{3}\end{array}$ & $\begin{array}{c}\text { Front_Sf }{ }^{3} \\
{ }^{*} \alpha_{7}\end{array}$ & $\begin{array}{c}\text { Back_Sf }{ }^{4} \\
{ }^{*} \alpha_{8}\end{array}$ & $\begin{array}{c}\text { SS_Sf }{ }^{5} \\
{ }^{*} \alpha_{10}\end{array}$ & $\begin{array}{l}\text { C.D. }{ }^{6} \\
\left(\mathbf{R}^{2}\right)\end{array}$ \\
\hline 1 & 194 & & -1.7 & & & & & 0.701 \\
\hline 2 & 196 & & -1.7 & & & & & 0.698 \\
\hline 3 & 168 & & -1.3 & & & & & 0.578 \\
\hline 4 & 202 & & -1.7 & & & & & 0.765 \\
\hline 5 & 232 & & -2.0 & & & & & 0.729 \\
\hline 6 & 228 & & -2.0 & & & & & 0.902 \\
\hline 7 & 282 & & & -9.3 & & & & 0.733 \\
\hline 8 & 185 & 3.5 & & -9.8 & 1.35 & & & 0.939 \\
\hline 9 & 183 & & -1.5 & & & & & 0.576 \\
\hline 10 & 114 & & & & & -2.4 & & 0.605 \\
\hline 11 & 253 & & -2.3 & & & & & 0.878 \\
\hline 12 & 203 & & -1.7 & & & & & 0.505 \\
\hline 13 & 230 & & -2.1 & & & & & 0.729 \\
\hline 14 & 140 & & & & & & -2.8 & 0.727 \\
\hline 15 & 183 & & -1.5 & & & & & 0.598 \\
\hline 16 & 237 & & -2.2 & & & & & 0.755 \\
\hline 17 & 152 & & -1.2 & & & & & 0.512 \\
\hline 18 & 177 & & -1.4 & & & & & 0.677 \\
\hline 19 & 202 & & -1.7 & & & & & 0.566 \\
\hline 20 & 211 & & -1.8 & & & & & 0.631 \\
\hline
\end{tabular}

${ }^{1}$ Constant term of each equation.

${ }^{2}$ Body mass index.

${ }^{3}$ Front thoracic skinfold.

${ }^{4}$ Back thoracic skinfold.

5 Subscapular thoracic skinfold.

${ }^{6}$ Coefficient of determination. All p-values were less than 0.05

${ }^{*} \alpha_{i}$ is the constant of each term.

NOTE: the remainder of coefficients of equation (2) are not expressed in this table due to the value of them is zero. 
Table 5. Volume determinations differences obtained by TIE4sys, using the 3 configurations of electrodes (EIT image, 3,4-11,12 and 4,5-12,13 electrodes configurations), and those obtained by the pneumotachometer (gold standard). The differences are expressed as percentage (\%).

\begin{tabular}{|c|c|c|c|c|c|c|c|}
\hline \multirow{2}{*}{$V_{G^{1}}$} & \multirow{2}{*}{$\begin{array}{l}\text { Vpneumotach } \\
\text { (l) }\end{array}$} & \multicolumn{2}{|c|}{$\begin{array}{l}\text { Using EIT Image } \\
\text { (16-electrodes) }\end{array}$} & \multicolumn{2}{|c|}{$\begin{array}{c}\text { Using } 3,4-11,12 \text { electrode } \\
\text { configuration }\end{array}$} & \multicolumn{2}{|c|}{$\begin{array}{l}\text { Using 4,5-12,13 electrode } \\
\text { configuration }\end{array}$} \\
\hline & & $\begin{array}{l}\text { VTIE4sys }^{3} \\
\text { (l) }\end{array}$ & $\begin{array}{c}\text { Error }^{4} \\
(\%)\end{array}$ & $\begin{array}{l}\text { VTIE4sys }^{5} \\
\text { (l) }\end{array}$ & $\begin{array}{c}\text { Error }^{6} \\
(\%)\end{array}$ & $\begin{array}{l}\text { VTIE4sys }^{7} \\
\text { (l) }\end{array}$ & $\begin{array}{c}\text { Error }^{8} \\
(\%)\end{array}$ \\
\hline 1 & $0.571 \pm 0.116$ & $0.586 \pm 0.150$ & 13 & $0.596 \pm 0.185$ & 20 & $0.685 \pm 0.291$ & 32 \\
\hline 2 & $0.571 \pm 0.121$ & $0.592 \pm 0.132$ & 14 & $0.554 \pm 0.178$ & 15 & $0.603 \pm 0.281$ & 32 \\
\hline 3 & $0.576 \pm 0.119$ & $0.587 \pm 0.140$ & 14 & $0.553 \pm 0.198$ & 21 & $0.607 \pm 0.298$ & 35 \\
\hline 4 & $0.610 \pm 0.150$ & $0.622 \pm 0.162$ & 11 & $0.563 \pm 0.157$ & 18 & $0.591 \pm 0.241$ & 33 \\
\hline 5 & $0.588 \pm 0.125$ & $0.548 \pm 0.118$ & 13 & $0.535 \pm 0.139$ & 16 & $0.473 \pm 0.095$ & 25 \\
\hline 6 & $0.611 \pm 0.152$ & $0.546 \pm 0.166$ & 9 & $0.515 \pm 0.159$ & 15 & $0.523 \pm 0.250$ & 31 \\
\hline 7 & $0.555 \pm 0.083$ & $0.548 \pm 0.110$ & 14 & $0.637 \pm 0.167$ & 21 & $0.563 \pm 0.870$ & 159 \\
\hline 8 & $0.644 \pm 0.139$ & $0.592 \pm 0.209$ & 22 & $0.627 \pm 0.211$ & 23 & $0.287 \pm 1.073$ & 163 \\
\hline 9 & $0.584 \pm 0.118$ & $0.631 \pm 0.139$ & 12 & $0.582 \pm 0.132$ & 16 & $0.643 \pm 0.254$ & 27 \\
\hline 10 & $0.496 \pm 0.043$ & $0.508 \pm 0.078$ & 11 & $0.568 \pm 0.131$ & 19 & $0.591 \pm 0.180$ & 28 \\
\hline 11 & $0.553 \pm 0.140$ & $0.542 \pm 0.124$ & 16 & $0.507 \pm 0.144$ & 12 & $0.483 \pm 0.167$ & 34 \\
\hline 12 & $0.569 \pm 0.127$ & $0.531 \pm 0.194$ & 24 & $0.490 \pm 0.124$ & 10 & $0.498 \pm 0.077$ & 25 \\
\hline 13 & $0.576 \pm 0.139$ & $0.575 \pm 0.126$ & 12 & $0.509 \pm 0.110$ & 14 & $0.569 \pm 0.109$ & 30 \\
\hline 14 & $0.577 \pm 0.121$ & $0.531 \pm 0.146$ & 12 & $0.610 \pm 0.120$ & 17 & $0.451 \pm 0.157$ & 29 \\
\hline 15 & $0.560 \pm 0.120$ & $0.562 \pm 0.235$ & 31 & $0.471 \pm 0.144$ & 11 & $0.552 \pm 0.285$ & 32 \\
\hline 16 & $0.560 \pm 0.127$ & $0.562 \pm 0.116$ & 16 & $0.483 \pm 0.102$ & 12 & $0.520 \pm 0.089$ & 30 \\
\hline 17 & $0.567 \pm 0.106$ & $0.636 \pm 0.129$ & 8 & $0.654 \pm 0.207$ & 23 & $0.758 \pm 0.274$ & 31 \\
\hline 18 & $0.551 \pm 0.124$ & $0.582 \pm 0.152$ & 10 & $0.508 \pm 0.162$ & 14 & $0.611 \pm 0.296$ & 35 \\
\hline 19 & $0.575 \pm 0.128$ & $0.556 \pm 0.129$ & 14 & $0.647 \pm 0.097$ & 11 & $0.550 \pm 0.084$ & 25 \\
\hline 20 & $0.601 \pm 0.132$ & $0.605 \pm 0.145$ & 14 & $0.546 \pm 0.111$ & 13 & $0.568 \pm 0.116$ & 25 \\
\hline & & Mean & 15 & Mean & 16 & Mean & 43 \\
\hline & & $\mathrm{SD}^{9}$ & 6 & $\mathrm{SD}^{9}$ & 4 & $\mathrm{SD}^{9}$ & 41 \\
\hline
\end{tabular}

${ }^{1}$ Validation groups. In all of them was assessed the calibration equations determined by the 3 configurations of electrodes.

${ }^{2}$ Volume determinations obtained by pneumotachometer (gold standard).

${ }^{3}$ Volume determinations obtained by TIE4sys using EIT image (16-electrodes configuration).

${ }^{4}$ Error (in percentage) of the volume determinations obtained by TIE4sys, using EIT image, respect to the volume measurements obtained by pneumotachometer.

${ }^{5}$ Volume determinations obtained by TIE4sys using 3,4-11,12 electrodes configuration.

${ }^{6}$ Error (in percentage) of the volume determinations obtained by TIE4sys, using 3,4-11,12 electrode configuration, respect to the volume measurements obtained by pneumotachometer.

${ }^{7}$ Volume determinations obtained by TIE4sys using 4,5-12,13 electrodes configuration.

${ }^{8}$ Error (in percentage) of the volume determinations obtained by TIE4sys, using 4,5-12,13 electrode configuration, respect to the volume measurements obtained by pneumotachometer.

${ }^{9}$ Standard deviation of errors (\%). 
Table 6. Analysis of volume measurements obtained by pneumotachometer and TIE4sys, using 1) EIT image, 2) 3.11 electrodes configuration and 2) 4.12 electrodes configuration.

\begin{tabular}{|c|c|c|c|c|c|c|c|c|c|}
\hline \multirow{2}{*}{$\mathrm{VG}^{1}$} & \multicolumn{3}{|c|}{$\begin{array}{c}\text { Vpneumotach - VTIE4sys } \\
\text { EIT image }^{2}\end{array}$} & \multicolumn{3}{|c|}{$\begin{array}{c}\text { Vpneumotach - VTIE4sys } \\
\text { 3,4-11,12 electrode configuration }\end{array}$} & \multicolumn{3}{|c|}{$\begin{array}{c}\text { Vpneumotach - VTIE4sys } \\
\text { 4,5-12,13 electrode configuration }\end{array}$} \\
\hline & $\begin{array}{l}\text { t-test } \\
(\mathbf{p})^{5}\end{array}$ & $\begin{array}{l}\text { Levene's } \\
\text { p-value }\end{array}$ & $\begin{array}{l}\text { Correlation } \\
\mathbf{r}(\mathbf{p}<0.05)^{7}\end{array}$ & $\begin{array}{l}\text { t-test } \\
(\mathbf{p})^{5}\end{array}$ & $\begin{array}{l}\text { Levene's } \\
\text { p-value }\end{array}$ & $\begin{array}{l}\text { Correlation } \\
\mathbf{r}(\mathbf{p}<0.05)^{7}\end{array}$ & $\begin{array}{l}\text { t-test } \\
(\mathbf{p})^{5}\end{array}$ & $\begin{array}{l}\text { Levene's } \\
\text { p-value }\end{array}$ & $\begin{array}{l}\text { Correlation } \\
\mathbf{r}(\mathbf{p}<0.05)^{7}\end{array}$ \\
\hline 1 & 0.585 & 0.580 & 0.867 & 0.558 & 0.160 & 0.801 & 0.119 & 0.162 & 0.964 \\
\hline 2 & 0.467 & 0.972 & 0.801 & 0.616 & 0.351 & 0.903 & 0.637 & 0.174 & 0.885 \\
\hline 3 & 0.730 & 0.858 & 0.807 & 0.608 & 0.115 & 0.810 & 0.677 & 0.167 & 0.878 \\
\hline 4 & 0.617 & 0.937 & 0.904 & 0.274 & 0.718 & 0.741 & 0.808 & 0.600 & $0.542^{(*)}$ \\
\hline 5 & 0.196 & 0.814 & 0.796 & 0.154 & 0.493 & 0.750 & 0.059 & 0.745 & $0.163^{(*)}$ \\
\hline 6 & 0.015 & 0.703 & 0.938 & 0.019 & 0.924 & 0.836 & 0.019 & 0.924 & 0.836 \\
\hline 7 & 0.808 & 0.424 & 0.713 & 0.093 & 0.074 & 0.755 & 0.981 & 0.085 & $-0.123^{(*)}$ \\
\hline 8 & 0.332 & 0.300 & 0.750 & 0.767 & 0.644 & 0.719 & 0.369 & 0.11 & $0.218^{(*)}$ \\
\hline 9 & 0.088 & 0.759 & 0.871 & 0.967 & 0.829 & 0.735 & 0.318 & 0.274 & 0.900 \\
\hline 10 & 0.526 & 0.039 & 0.779 & 0.073 & 0.001 & 0.865 & 0.096 & 0.007 & 0.944 \\
\hline 11 & 0.734 & 0.989 & 0.785 & 0.089 & 0.813 & 0.892 & 0.321 & 0.491 & $0.280^{(*)}$ \\
\hline 12 & 0.453 & 0.314 & 0.709 & 0.007 & 0.710 & 0.889 & 0.197 & 0.596 & $0.108^{(*)}$ \\
\hline 13 & 0.954 & 0.838 & 0.863 & 0.056 & 0.679 & 0.804 & 0.909 & 0.651 & $0.050^{(*)}$ \\
\hline 14 & 0.093 & 0.708 & 0.891 & 0.371 & 0.571 & $0.664^{(*)}$ & 0.071 & 0.369 & $0.283^{(*)}$ \\
\hline 15 & 0.969 & 0.128 & $0.685^{(*)}$ & 0.005 & 0.519 & 0.903 & 0.912 & 0.198 & 0.924 \\
\hline 16 & 0.956 & 0.751 & 0.745 & 0.016 & 0.986 & 0.845 & 0.521 & 0.991 & $-0.141^{(*)}$ \\
\hline 17 & 0.003 & 0.279 & 0.950 & 0.097 & 0.268 & 0.852 & 0.018 & 0.169 & 0.953 \\
\hline 18 & 0.169 & 0.656 & 0.934 & 0.165 & 0.537 & 0.882 & 0.416 & 0.157 & 0.886 \\
\hline 19 & 0.518 & 0.809 & 0.809 & 0.015 & 0.506 & 0.879 & 0.629 & 0.543 & $0.164^{(*)}$ \\
\hline 20 & 0.883 & 0.872 & 0.813 & 0.092 & 0.682 & 0.801 & 0.556 & 0.983 & $0.278^{(*)}$ \\
\hline $\mathrm{M}^{8}$ & 0.505 & 0.637 & 0.821 & 0.252 & 0.529 & 0.816 & 0.432 & 0.420 & 0.500 \\
\hline $\mathrm{SD}^{9}$ & 0.329 & 0.288 & 0.079 & 0.292 & 0.287 & 0.070 & 0.322 & 0.317 & 0.405 \\
\hline
\end{tabular}

${ }^{(*)}$ Non significant correlations ( $\left.\mathrm{p}>0.05\right)$.

${ }^{1} 20$ validation groups. In each one was assessed its respective calibration equation.

${ }^{2}$ Assessment of volume differences obtained by TIE4sys, using EIT image, and pneumotachometer.

${ }^{3}$ Assessment of volume differences obtained by TIE4sys, using the configuration of electrodes 3,4-11,12, and pneumotachometer.

${ }^{4}$ Assessment of volume differences obtained by TIE4sys, using the configuration of electrodes 4,5-12,13, and pneumotachometer.

${ }^{5}$ The volume differences were assessed by a Student's t-test, setting a significant p-value at 0.05 .

${ }^{6}$ The variance differences of the volume determinations obtained by both devices was performed by Levene's test, setting a significant p-value at 0.05 .

${ }^{7}$ The correlation analysis of volume determinations obtained by both monitoring devices was done by a Peason's correlation test.

${ }^{8}$ Mean value.

${ }^{9}$ Standard deviation value. 
